\title{
Evaluation of the turbine pocket spirometer
}

\author{
K A GUNAWARDENA, K HOUSTON, A P SMITH \\ From Riyadh Military Hospital, Riyadh, Saudi Arabia, and Llandough Hospital, Penarth, South Glamorgan
}

ABSTRACT: A compact electronic spirometer, the turbine pocket spirometer, which measures the $\mathrm{FEV}_{1}$, forced vital capacity (FVC), and peak expiratory flow (PEF) in a single expiration, was compared with the Vitalograph and the Wright peak flow meter in 99 subjects $\left(\mathrm{FEV}_{1}\right.$ range 0.40-5.50 litres; FVC 0.58-6.48 1; PEF 40-650 $1 \mathrm{~min}^{-1}$ ). The mean differences between the machines were small -0.051 for $\mathrm{FEV}_{1}, 0.051$ for $\mathrm{FVC}$, and $11.61 \mathrm{~min}^{-1}$ for PEF, with the limits of agreement at $\pm 0.251, \pm 0.481$, and $\pm 52.21 \mathrm{~min}^{-} 1$ respectively. The wide limits of agreement for the PEF comparison were probably because of the difference in the technique of blowing: a fast, long blow was used for the pocket spirometer and a short, sharp one for the Wright peak flow meter. The $\mathrm{FEV}_{1}$ and FVC showed a proportional bias of around 4-5\% in favour of the Vitalograph. The repeatability coefficient for the pocket spirometer $\mathrm{FEV}_{1}$ was $0 \cdot 181$, for FVC 0.221 , and for PEF 311 $\min ^{-1}$. These compared well with the repeatability coefficients of the Vitalograph and the Wright peak flow meter, which gave values of $0 \cdot 181,0 \cdot 281$, and $271 \mathrm{~min}^{-1}$ respectively. At flow rates of over $6001 \mathrm{~min}^{-1}$ the resistance of the pocket spirometer marginally exceeded the American Thoracic Society recommendations. The machine is easy to operate and portable, and less expensive than the Vitalograph and Wright peak flow meter combined. It can be recommended for general use.

Simple measurements of pulmonary function, such as $\mathrm{FEV}_{1}$, forced vital capacity (FVC), and peak expiratory flow (PEF) are now widely used in the monitoring of patients with airflow limitation both in hospital and at home. In occupational medicine and clinical trials repetitive measurements of these indices may be needed in large numbers of subjects. Inexpensive, portable devices for measuring the PEF have been available for clinical use for many years. ${ }^{1-3}$ Instruments for measuring FEV ${ }_{1}$ and FVC, however, are often expensive and bulky. In 1982 Chowienczyk and Lawson ${ }^{4}$ described a pocket sized device for measuring the $\mathrm{FEV}_{1}$, and FVC. This instrument gave measurements that agreed well with those of the Ohio spirometer (Ohio Inc, Houston, Texas) when they were connected in series. The device, which the authors called the turbine spirometer, has now been developed further to measure the PEF. The object of the present study was to evaluate this new device in a clinical setting by comparing its performance with that of the Vitalograph (Vitalograph Ltd, Maids Moreton House, Buckingham) and the Wright peak flow meter

Address for reprint requests: Dr K A Gunawardena, Riyadh Military Hospital, PO Box 7897, Riyadh 11159, Saudi Arabia.

Accepted 13 January 1987
(Airmed, Clement Clarke International Ltd, Harlow, Essex), which are widely used and whose reliability has been established. ${ }^{5-9}$

\section{Methods}

A turbine pocket spirometer loaned by the manufacturers (Micro Medical Instruments, PO Box 6 , Rochester, Kent) was compared with a model S Vitalograph and a standard Wright peak flow meter that were in routine use in the lung function laboratory. The turbine pocket spirometer (fig 1) weighs $400 \mathrm{~g}$ and is powered by a single 9 v (PP3) battery. The unit consists of a fixed turbine, which generates a rotational flow that drives a low inertia vane. The rotation of the vane is converted into electrical pulses by means of an infrared light emitting diode and a photodiode sensor enclosed in the turbine housing. These electrical pulses are converted into $\mathrm{FEV}_{1}, \mathrm{FVC}$, and PEF measurements by means of a microprocessor in the control unit and are displayed digitally. The pocket spirometer is very easy to operate. When the instrument is switched on no warm up time is necessary, and when the "reset" button is pressed all the readings are converted to zero. The subject is then instructed to perform a forced vital capacity manoeuvre into the mouthpiece. The FVC, $\mathrm{FEV}_{1}$, and PEF readings can be read directly off the 


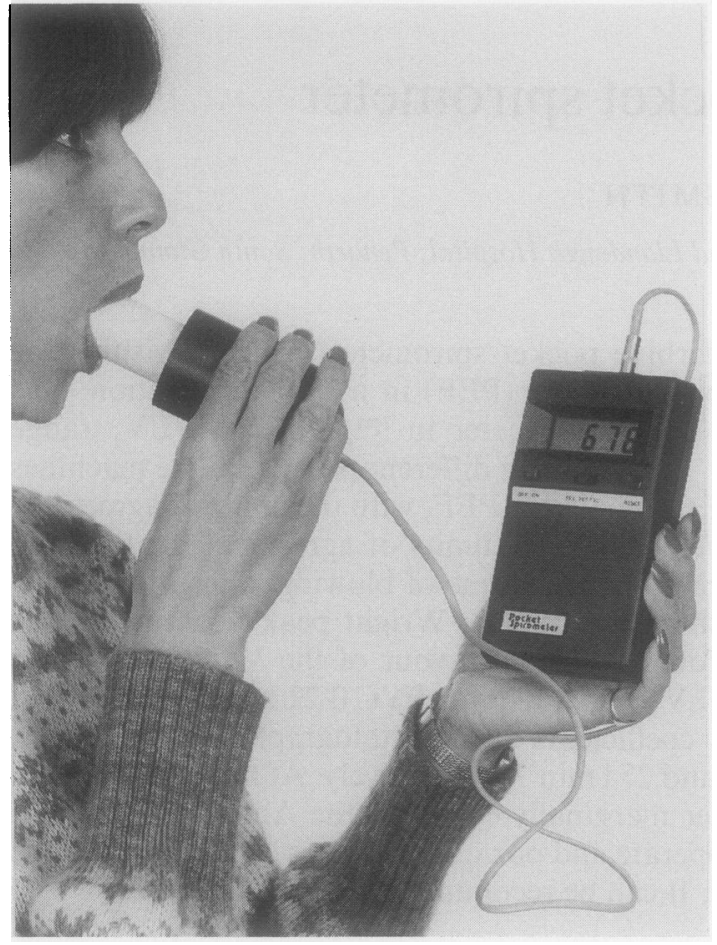

Fig 1 The turbine pocket spirometer in use.

display by means of the selector switch provided. The readings are stored indefinitely until the reset button is pressed again. The unit at present costs $£ 340$.

Volume calibration was effected with a 1.0 litre syringe so that the volume displayed on the pocket spirometer agreed with the volume indicated on the ATPS scale of the Vitalograph. The linearity of the Vitalograph was checked further with increments of 1.0 litre up to 6.0 litres. The percentage error was zero for 1.01 , but increased slightly at higher volumes, the error at 5.01 being $+2.6 \%$. The calibration of the Wright peak flow meter was checked against a Fisher Controls rotameter (Fisher Controls Ltd, Rotameter Works, Croydon, Surrey) as described by Cotes, ${ }^{10}$ but with correction of the observed rotameter flow for both the temperature and the back pressure. The observed meter readings were all within $10 \%$ of the expected readings, the percentage error being $+5.9 \%$ at $200 \mathrm{lmin}^{-1}$ and $-8.3 \%$ at $8001 \mathrm{~min}^{-1}$, indicating a tendency for the Wright peak flow meter to overread at low values and underread at high values.

Ninty nine subjects took part in the main study. They were drawn from the staff and the patients attending the outpatient chest clinics at the Llandough Hospital. Most subjects were regular attenders at the chest clinics and were familiar wit $\overrightarrow{\overrightarrow{\vec{D}_{3}}}$ the forced expiratory manoeuvre. The nature and purpose of the study were explained, and after the subject had become familiar with the instrumente each provided three technically satisfactory reading 8 with the pocket spirometer, three with the Vitalograph, and three with the Wright peak flow meter. In the case of the pocket spirometer as well as the Wright peak flow meter the assessment of the adequacy of effort could be made only by observing the subject. The instrument to be blown into first was varied systematically, so that the results would not be biased by the effects of training or fatigue. For eact comparison the best of the three readings was use For FEV 1 and FVC the volumes indicated on the BTPS scale of the Vitalograph were compared with the direct digital readout from the pocket spirometer.

Since patients are normally instructed to produce $Q$ short, sharp blow into the Wright peak flow meter b\$ a prolonged fast blow for measurement of the FVe and $\mathrm{FEV}_{1}$, a further study was carried out to compare the PEF readings obtained by a short, sharp blow with the PEF obtained by a prolonged fast bloveo Data for short, sharp versus prolonged blows on thê Wright peak flow meter were obtained from it subjects and similar data for the pocket spirometef were obtained from 41 subjects.

The resistance of the pocket spirometer was measured as described by Cotes. ${ }^{10}$

The results were analysed by the statistical methods described by Bland and Altman. ${ }^{11} 12$

\section{Results}

COMPARISON OF THE INSTRUMENTS

In the 99 subjects tested, $\mathrm{FEV}_{1}$ ranged from 0.40 t 5.50 litres, FVC from 0.58 to 6.48 litres, and PEFQ from 40 to $650 \mathrm{l} / \mathrm{min}$. Figure 2 shows the difference between measurements obtained from the two machines plotted against the average of the two readings. The mean difference for the $\mathrm{FEV}_{1}$ reading was 0.05 1 (SD 0.13), for FVC 0.05 1 (SD 0.24) and for PEF $11.61 \mathrm{~min}^{-1}$ (SD 26). Table 1 gives the $95 \%$ confidence limits for the estimates of the meap difference, and the "limits of agreement."11

The differences were negatively correlated with the average reading of $\mathrm{FEV}_{1}(\mathrm{r}=-0.39, t=4 \cdot 18$ $\mathrm{df}=97 ; \mathrm{p}<0.001$ ), and weakly negatively correlated with average FVC $(\mathrm{r}=-0.198, t=1.99, \mathrm{df}=9$. $p<0.05$ ); but there was no correlation in the case PEF. The slopes of the regressions for difference versus average were -0.051 for $\mathrm{FEV}_{1}(95 \%$ limito -0.075 to -0.027$)$ and -0.041 for FVC $(95 \%$ limis -0.083 to 0.000 ). There was thus a significa proportional bias for $\mathrm{FEV}_{1}$, with the Vitalograpt giving the higher readings at higher values of $\mathrm{FEV}_{\text {(e) }}^{\varrho}$ 


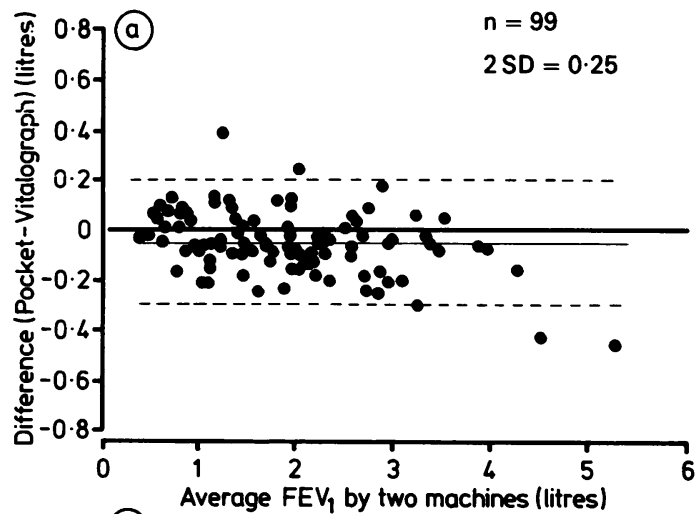

Table 1 Confidence limits for the estimates of mean difference (pocket spirometer-Vitalograph/Wright peak flow meter) and limits of agreement

\begin{tabular}{|c|c|c|c|}
\hline & & Estimate & $95 \%$ limits \\
\hline $\mathrm{FEV}_{1}(\mathrm{l})$ & $\begin{array}{l}\overline{\mathrm{d}} \\
\mathrm{s} D \\
\frac{\mathrm{d}}{\mathrm{d}}+2 \mathrm{SD}\end{array}$ & $\begin{array}{r}-0.05 \\
0.13 \\
-0.30 \\
0.20\end{array}$ & $\begin{array}{r}-0.075 \text { to }-0.025 \\
-0.342 \text { to }-0.255 \\
0.157 \text { to } 0.245\end{array}$ \\
\hline FVC (l) & $\begin{array}{l}\overline{\mathrm{d}} \\
\mathrm{S} D \\
\overline{\mathrm{d}}-2 \mathrm{SD} \\
\overline{\mathrm{d}}+2 \mathrm{SD}\end{array}$ & $\begin{array}{r}-0.05 \\
0.24 \\
-0.53 \\
0.43\end{array}$ & $\begin{array}{r}0.00 \text { to }-0.10 \\
-0.611 \text { to }-0.488 \\
0.347 \text { to } 0.513\end{array}$ \\
\hline PEF $\left(1 \min ^{-1}\right)$ & $\begin{array}{l}\overline{\mathrm{d}} \\
\mathrm{S} D \\
\overline{\mathrm{d}}-2 \mathrm{SD} \\
\overline{\mathrm{d}}+2 \mathrm{SD}\end{array}$ & $\begin{array}{r}-11 \cdot 6 \\
26 \cdot 1 \\
-63 \cdot 6 \\
40 \cdot 4\end{array}$ & $\begin{aligned}-16.8 & \text { to }-6.4 \\
-68.1 & \text { to }-59.1 \\
35.9 & \text { to } 44.9\end{aligned}$ \\
\hline
\end{tabular}

FVC - forced vital capacity; PEF - peak expiratory flow; $\bar{d}$-mean difference; $S D$-standard deviation; $\bar{d}-2 \mathrm{SD}=$ lower limit of agreement; $\bar{d}+2 S D$ - upper limit of agreement.

\section{SHORT VERSUS LONG BLOWS}

The results of the comparisons of the short sharp blows versus the prolonged fast blows are shown in figure 3. For the Wright peak flow meter the mean
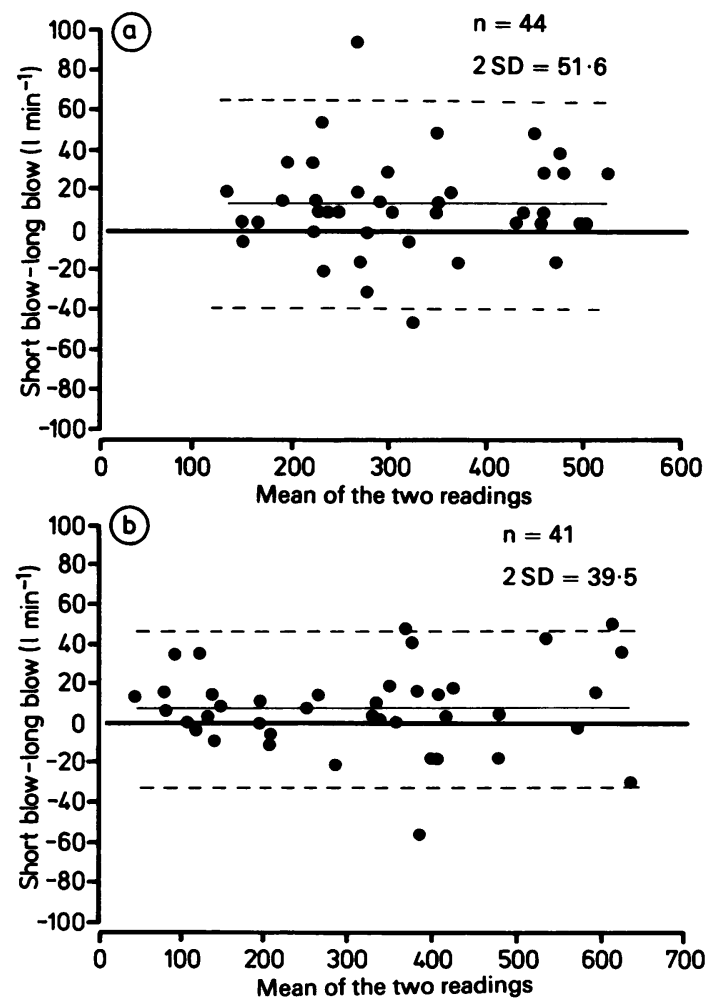

This proportional bias would somewhat overestimate the mean and the SD of the differences for FEV and $_{1}$ FVC. Logarithmic transformation of the data to remove this relationship was not helpful, as it tended to disproportionately increase the scatter at low readings.

Fig 3 Comparisons of short, sharp blows with prolonged fast blows for the measurement of peak expiratory flow on (a) the Wright peak flow meter and (b) the pocket spirometer. - mean; - - - limits of agreement. 
Table 2 Confidence limits for the estimates of the mean differences (short blow-long blow)

\begin{tabular}{clrrr}
\hline & & $\begin{array}{c}\text { Estimate } \\
\left(\text { min }^{-1}\right)\end{array}$ & \multicolumn{1}{c}{$95 \%$ limits } \\
\hline Wright peak & $\overline{\mathrm{d}}$ & 14.1 & 6.25 to & 21.93 \\
flow meter & $\mathrm{S} D$ & 25.8 & & \\
& $\overline{\mathrm{d}}-2 \mathrm{SD}$ & -37.5 & -51.09 to -23.91 \\
& $\overline{\mathrm{d}}+2 \mathrm{SD}$ & 65.7 & 52.11 to 79.29 \\
Pocket & $\overline{\mathrm{d}}$ & 7.5 & 1.29 to & 13.74 \\
spirometer & $\mathrm{S} D$ & 19.7 & -42.79 to -21.21 \\
& $\overline{\mathrm{d}}-2 \mathrm{SD}$ & -32.0 & -42.0 \\
& $\overline{\mathrm{d}}+2 \mathrm{SD}$ & 47.0 & 36.21 to & 57.79 \\
\hline
\end{tabular}

Abbreviations as in table 1 .

difference between the short and the long blows was $14.11 \mathrm{~min}^{-1}$ (SD 25.8), the short blow producing higher readings than the long one. This difference was significant (paired $t=4.705$, df $=43 ; \mathrm{p}<0.001$ ). For the pocket spirometer the difference was less $-7 \cdot 5$ $1 /$ min (SD 19.7) - but still significant (paired $t=2.44$, $\mathrm{df}=40 ; \mathrm{p}<0.02$ ). The $95 \%$ confidence limits for the estimates of the mean differences and the limits of agreement are given in table 2 .

\section{REPEATABILITY}

The repeatability for each of the measurements on the series of 99 subjects was assessed by calculating the standard deviation of the difference between the two closest values. The defined repeatability coefficients are twice these standard deviations. ${ }^{11}$ This would indicate the $95 \%$ probability limit within which the best two out of the three readings would lie. For the Vitalograph $\mathrm{FEV}_{1}$ the repeatability coefficient was $0.18 \mathrm{l}$, for FVC $0.28 \mathrm{l}$, and for the Wright machine's PEFR $271 \mathrm{~min}^{-1}$. The corresponding values for the pocket spirometer were: $\mathrm{FEV}_{1} 0 \cdot 18 \mathrm{l}$, FVC $0.22 \mathrm{l}$, and for PEF $311 \mathrm{~min}^{-1}$. Thus the repeatability of the readings on the pocket spirometer appeared to be as

Table 3 Resistance of the pocket spirometer at different flow rates (actual flow rates calculated by correcting the observed flow rate for both the temperature and the back pressure)

\begin{tabular}{llcl}
\hline $\begin{array}{l}\text { Observed } \\
\text { rotameter flow } \\
\left(l \text { min }^{-1}\right)\end{array}$ & $\begin{array}{l}\text { Actual flow } \\
\left(l \text { min }^{-1}\right)\end{array}$ & $\begin{array}{l}\text { Back pressure } \\
\left(\mathrm{mm} \mathrm{H}_{2} \mathrm{O}\right)\end{array}$ & $\begin{array}{l}\text { Resistance } \\
\left(\mathrm{mm} \mathrm{H}_{2} \mathrm{Ols}^{-1}\right)\end{array}$ \\
\hline 100 & 98 & $6 \cdot 2$ & $3 \cdot 8$ \\
150 & 148 & $13 \cdot 0$ & $5 \cdot 3$ \\
200 & 198 & $20 \cdot 2$ & $6 \cdot 1$ \\
250 & 249 & $29 \cdot 0$ & $7 \cdot 0$ \\
300 & 300 & $43 \cdot 2$ & $8 \cdot 6$ \\
350 & 352 & $59 \cdot 4$ & $10 \cdot 1$ \\
400 & 405 & $74 \cdot 0$ & $11 \cdot 0$ \\
450 & 459 & $94 \cdot 4$ & $12 \cdot 3$ \\
500 & 514 & $114 \cdot 4$ & $13 \cdot 3$ \\
550 & 570 & $135 \cdot 1$ & $14 \cdot 2$ \\
600 & 627 & $160 \cdot 2$ & $15 \cdot 3$ \\
650 & 687 & 188.9 & $16 \cdot 5$ \\
\hline
\end{tabular}

good as those for the Vitalograph and the Wright peak flow meter.

The back pressure generated by the pocket spirometer at various flow rates and resistance of the instrument are shown in table 3.

\section{Discussion}

Electronic spirometers offer considerable advantages over water filled or bellows spirometers in terms of portability and ease of operation. The direct digit袲! readout offered by most of these instruments is alson major time saving advantage. Previous studię, however, have shown that electronic spirometeress could be seriously inaccurate by comparison with the standard volume displacement spirometers. ${ }^{73-15}$ 응

The device tested in this study has been shown to produce results for $\mathrm{FEV}$, and FVC that agree closeny with those obtained with the Ohio spirometer when the machines are connected in series. We compared $\mathbb{G}_{\mathrm{G}} \mathrm{t}$ with the Vitalograph and found that the meg్gn differences for both $\mathrm{FEV}_{1}$ and the FVC were in the region of 0.05 litres. The limits of agreemess, however, seemed somewhat wide, being around \pm 0.251 for $\mathrm{FEV}_{1}$, and around \pm 0.481 for FVE. Since we used the machines separately, we cousd expect the scatter of the differences to be wider than the machines were connected in series. A proportiorgl bias would also increase the estimated random error of the difference between the two methods. ${ }^{16}$ e found that the difference in the readings could around $5 \%$ for the $\mathrm{FEV}_{1}$, with the Vitalograph producing higher readings than the pockeft spirometer. It is difficult to know which machipie actually gives the "true" value. Indeed, the Vitalograph used for the study showed an error of $+2.6 \%$ at the 5.01 calibration. It is also possible that the Vitalograph overshoots at high flow rates, așa result of inertia effects-an observation not uncommonly made when one tries to calibrate the Vitalograph with a syringe. Observations reported by Wever et $a^{6}$ suggests a proportional bias of $6-8 \% \frac{1}{\mathrm{in}}$ favour of the Vitalograph when it was compared with the Stead-Wells spirometer, and the data presented Gardner et $a^{17}$ also indicate that the Vitalograph could over-read at high flow rates.

The question of whether the pocket spirometer could be used interchangeably with the Vitalogragh and the Wright peak flow meter depends on the relative biases and on the relative values of 得e repeatability coefficients and the limits of agreeme@t. If the observed bias is not clinically significant, and if the differences between the machines are not too large in relation to the differences between repeated measurements by the same method, then one may lse the machines interchangeably. In other words, Afe 
limits of agreement should not be too large in relation to the repeatability coefficient for the established method.

For the $\mathrm{FEV}_{1}$ comparison (disregarding the proportional bias), the limits of agreement of \pm 0.251 seem quite acceptable, considering that the repeatability coefficient of the $\mathrm{FEV}_{1}$ for the Vitalograph is of the order of $0 \cdot 18 \mathrm{l}$. For the FVC, however, with a repeatability coefficient of 0.281 , the limits of agreement of $\pm 0.48 \mathrm{l}$, even though not excessive, appear less than ideal. The lack of a comparable endpoint to the expiratory manoeuvre may explain part of the variation between the machines. The pocket spirometer does not provide a visual display of the spirographic curve, and therefore the adequacy of effort and the end of expiration are more difficult to judge than with the Vitalograph, especially in patients with severe airflow obstruction. Despite this, the repeatability coefficient of 0.221 for the FVC on the pocket spirometer was marginally better than with the Vitalograph.

For PEF, the coefficients of repeatability for the Wright peak flow meter and for the pocket spirometer were broadly similar, and the mean difference in the readings neglegible. The limits of agreement of $\pm 52.21 / \mathrm{min}$ were, however, wide, but were of the order that would be expected from comparison of the readings obtained with a short, sharp blow with the readings obtained with a prolonged blow on the Wright peak flow meter. Perhaps the wide limits of agreement between the two machines could be explained by the fact that we used a prolonged blow for the pocket spirometer and a short, sharp one for the Wright peak flow meter. Possibly better agreement would have been obtained if we had used similar type of blows for the two machines.

The minimal spirometry standards laid down by the American Thoracic Society ${ }^{18}$ require the resistance of a spirometer used for measuring the $\mathrm{FEV}_{1}$ to be less than $1.5 \mathrm{~cm}$ of water $1^{-1} \mathrm{~s}^{-1}$ at a flow rate of $121 \mathrm{~s}^{-1}$. With the pocket spirometer the resistance exceeds $1.5 \mathrm{~cm}$ of water $1^{-1} \mathrm{~s}^{-1}$ at a flow rate of around $10 \mathrm{l} \mathrm{s}^{-1}$ (table 3). This, however, should not be a serious drawback to the clinical use of the instrument.

The major disadvantage of the pocket spirometer is the lack of a visual display of the spirographic curve. Despite this, its overall performance was impressive. It is eminently portable and easy to use, and gives accurate and reliable readings if the tests are performed with sufficient care. The tests can be performed rapidly with a lesser number of efforts on the part of the patient to obtain the three most commonly used parameters of ventilatory function. At $£ 340$ it is considerably cheaper than the combined cost of a model-S Vitalograph and a standard Wright peak flow meter (about $£ 820+£ 180$ ). The pocket spirometer should therefore prove to be a useful tool in a busy respiratory laboratory as well as in the doctor's surgery or in clinical and epidemiological research.

We thank Mrs G Collins, Mrs A Donkin, Mr G Hawkins, Mr J M Lucas, Mr D H Richards, Mr M J Saunders, Mr P Thomas, Miss S Tutt, and Miss F Williams of the lung function laboratory, Llandough Hospital, Penarth, for their assistance.

\section{References}

1 Wright WB, McKerrow CB. Maximum forced expiratory flow rate as a measure of ventilatory capacity. Br Med J 1959;ii:1041-7.

2 Wright BM. A miniature Wright peak flow meter. $\mathrm{Br}$ Med J 1978;ii:1627-8.

3 Perks WH, Cole M, Steventon RD, Tams IP, Prowse K. An evaluation of the Vitalograph pulmonary monitor. Br J Dis Chest 1981;75:161-4.

4 Chowienczyk PJ, Lawson CP. Pocket-sized device for measuring forced expiratory volume in one second and forced vital capacity. $\mathrm{Br} \mathrm{Med} J$ 1982;285:15-7.

5 Drew CDM, Hughes DTD. Characteristics of the Vitalograph spirometer. Thorax 1969;24:703-6.

6 Wever AMJ, Britton MG, Hughes DTD. Evaluation of two spirometers. A comparative study of the Stead-Wells and the Vitalograph spirometers. Chest 1976;70:244-50.

7 Wever AMJ, Britton MG, Hughes DTD, Van der Plas $\mathrm{KH}$, Wever-Hess J. Clinical evaluation of five spirometers: Monaghan M403, Pneumoscreen, Spirotron, Vicatest and Vitalograph. Eur J Respir Dis 1981;62:127-37.

8 Lockhart W, Smith DH, Mair A, Wilson WA. Practical experience with the peak flow meter. Br Med J 1960;i:37.

9 Shephard RJ. Some observation on peak expiratory flow. Thorax 1962;17:39-48.

10 Cotes JE. Lung function: assessment and application in medicine. 4th ed. Oxford: Blackwell Scientific Publications, 1979:25.

11 Bland JM, Altman DG. Statistical methods for assessing agreement between two methods of clinical measurement. Lancet 1986;i:307-10.

12 Altman DG, Bland JM. Measurement in medicine: the analysis of method comparison studies. Statistician 1983;32:307-17.

13 Fitzgerald MX, Smith AA, Gaensler EA. Evaluation of "electronic" spirometers. N Engl J Med 1973;289:1283-8.

14 Shanks DE, Morris JF. Clinical comparison of two electronic spirometers with a water-sealed spirometer. Chest 1976;4:461-6.

15 Gunawardena KA, Smith AP. An evaluation of the LA3 Mk.2 lung function analyser. Breath 1984;21:7-9.

16 Westgard JO, Hunt MR. Use and interpretation of common statistical tests in method-comparison studies. Clin Chem 1973;19:49-57.

17 Gardner RM, Hankinson JL, West BJ. Evaluating commercially available spirometers. Am Rev Respir Dis 1980;121:73-82.

18 American Thoracic Society. Snowbird workshop on standardization of spirometry. Am Rev Respir Dis 1979;119:831-8. 